\title{
MOTIVAÇÕES QUE INFLUENCIAM A PERMANÊNCIA DE JOVENS E ADULTOS NA ESCOLA: O QUE REVELAM AS NARRATIVAS DOS ESTUDANTES DO MUNICÍPIO DE MUTUÍPE?
}

\section{Motivations that influence the stay of young people and adults at school: what do the narratives of students in Mutuipe municiple reveal?}

Marilene Souza dos Santos - UFRB/BA, Brasil Maria Eurácia Barreto de Andrade - UFRB/BA, Brasil

\begin{abstract}
RESUMO: Este artigo buscou investigar as motivações que influenciam a permanência de jovens e adultos na escola para a continuidade e conclusão da Educação Básica. Interessou à pesquisa conhecer as ligações entre trajetórias de vida dos estudantes, retorno à escola e desejo de continuar e concluir a modalidade de ensino. Para tanto, o objetivo central pautou-se em compreender, à luz das narrativas dos estudantes do Colégio Doutor Julival Rebouças, localizado no município de Mutuípe-BA, os possíveis motivos que influenciam a permanência de jovens, adultos e idosos na escola para a continuidade e conclusão da Educação Básica. Assim, os caminhos metodológicos trilhados foram alicerçados na pesquisa de abordagem qualitativa (Minayo, 2001), e a pesquisa de campo como aporte balisador (Fonseca, 2002), apoiando-se na observação e entrevista semiestruturada como técnicas de recolha de dados (Gil, 1999; 2008). A análise dos dados foi revestida pela Análise do Conteúdo (Bardin, 2009), que utiliza procedimentos sistemáticos e objetivos de descrição do conteúdo das narrativas. Para fundamentar este trabalho, foram utilizados, principalmente, os estudos de Arroyo (2000); Freire (1991,1996); Ghiraldelli Junior (2008), dentre outros que contribuem para melhor compreender/explicar a problemática em pauta. Por meio das narrativas de quatro estudantes matriculados na Educação de Jovens e Adultos (EJA), por período igual ou superior a dois anos, foi possível inferir que a primeira evasão escolar resultou de prejuízos econômicos e sociais, e o retorno à escola representou a chance de recuperar o tempo perdido na infância, conseguir melhores inserções no mercado de trabalho formal, autonomia social e resgate da autoestima. São essas perspectivas que impulsionam os esforços em torno da permanência.
\end{abstract}

Palavras-chave: EJA. Permanência. Motivações. Narrativas.

\begin{abstract}
This article aimed to investigate the motivations that influence the permanence of young people and adults in school for the continuity and completion of basic education. Interested research understand the links between life trajectories of the students return to school and wish to continue and complete the learning mode. For this purpose, the central objective was to understand, in the light of the narratives of the students of Colégio Doutor Julival Rebouças, located in the municipality of Mutuípe-BA, the possible reasons that influence the permanence of young people, adults and the elderly in school for continuity and completion of Basic Education. Thus, the methodological paths followed were based on qualitative research (Minayo, 2001), and field research as a guiding input (Fonseca, 2002), based on observation and semi-structured interviews as
\end{abstract}


data collection techniques (Gil, 1999; 2008). Data analysis was covered by Content Analysis (Bardin, 2009), which uses systematic and objective procedures to describe the content of the narratives. To support this work, the studies of Arroyo (2000) were used mainly; Freire (1991, 1996); Ghiraldelli Junior (2008), among others that contribute to better understand / explain the issue at hand. Through the narratives of four students enrolled in Youth and Adult Education (EJA), for a period of two years or more, it was possible to infer that the first truancy resulted from economic and social losses, and return to school represented a chance to catch up in childhood, achieve better insertion in the formal labor market, social autonomy and recovery of self esteem. These are perspectives that drive efforts around the permanence.

Keywords: EJA. Permanence. Motivations. Narratives.

\section{INTRODUÇÃO}

Levantar o debate em torno das motivações para a permanência dos jovens e adultos na escola, partindo das suas narrativas, seus contextos e suas trajetórias de vida truncadas, marcadas por exclusões e negações de direitos, é, sem dúvida, trazer à tona resistência às ameaças sofridas no momento atual, sobretudo aos ataques a democracia, a educação pública e a modalidade da Educação de Jovens e Adultos (EJA) que vem sendo silenciada e invisibilizada nas suas políticas públicas e curriculares. O momento tenciona a ampliação do debate, da reflexão e da problematização acerca do lugar ocupado pela EJA no momento atual para que seja um campo de luta cada vez mais abraçado e defendido por profissionais e militantes que não se acomodam com as ameaças e estratégias perversas de grupos e movimentos antidemocráticos e capitalistas, mas, pelo contrário, que traga à tona as narrativas dos próprios sujeitos, com suas trajetórias de negação e de exclusão.

Evidenciar as motivações que influenciam a permanência dos jovens e adultos na escola a partir das suas próprias narrativas é reafirmar a importância de legitimar o legado de Freire por sua militância e sua crença no sujeito como referência basilar do processo de ensino-aprendizagem. Por defender a educação, a politização, a emancipação do sujeito, assim como, apostar em uma prática revestida de vida, de sentido, de diálogo e de implicação com o seu cotidiano e sua cultura. É neste sentido que este estudo se constitui como um movimento de resistência e de denúncia a concepções que deslegitimam os sujeitos e seus contextos de luta, e anuncia a necessidade de visibilizar

Educação, Psicologia e Interfaces, Volume 4, Número 3, p. 1-15, Julho/Setembro, 2020.

ISSN: 2594-5343. DOI: 10.37444/issn-2594-5343.v4i3.268 
Motivações que influenciam a permanência de jovens e adultos na escola: o que revelam as narrativas dos estudantes do município de Mutuípe?

as trajetórias de quem sofreu e sofre cotidiamanente com um sistema social perverso, segregador e excludente.

Diante deste contexto, faz-se importante destacar que intitula-se Educação de Jovens e Adultos (EJA) uma modalidade de ensino da Educação Básica que abrange uma quantidade diversa de processos e práticas formais e informais referentes a aquisição ou desenvolvimento de conhecimentos basilares, competências técnicas e profissionais, e habilidades relativas a fatores sociais e culturais (BRASIL, 1998). Apesar de sua trajetória histórica apresentar marcas de descontinuidade de ações e falseamento do sentido social da escolarização, a modalidade consiste em oferecer atendimento às pessoas que, por diferentes razões, não tiveram a oportunidade de iniciar ou dar continuidade ao processo de escolarização na infância.

Os sujeitos inseridos na EJA carregam experiências sobre a cultura letrada que adquiriram na convivência com o seu trabalho, com a sua vida cotidiana ou com sua breve passagem pela escola. Nessa perspectiva, convém refletir sobre os conteúdos curriculares no contexto das particularidades e inspirações dos diferentes sujeitos que compõem a modalidade, de modo que estratégias e metodologias para a orientação da permanência e o sucesso dos educandos sejam desenvolvidas. Assim, motivações que influenciam a permanência dos diferentes sujeitos apresentam-se como de grande relevância, pois percebe-se uma necessidade de assistir às dificuldades e expectativas desses sujeitos que carregam consequências do atraso e da falta de escolarização.

Diante do exposto, o estudo que resultou neste artigo foi mobilizado pela seguinte questão: quais os motivos que favorecem a permanência dos jovens, adultos e idosos na escola para a continuidade ou conclusão da Educação Básica? Assim, o objetivo central consiste em compreender, à luz das narrativas dos estudantes do Colégio Doutor Julival Rebouças, localizado no município de Mutuípe-BA, os possíveis motivos que influenciam a permanência de jovens, adultos e idosos ${ }^{1}$ na escola para a continuidade e conclusão da Educação Básica.

Para fundamentar este trabalho, foram utilizados, principalmente, os estudos de Arroyo (2000); Freire (1991,1996); Ghiraldelli Junior (2008) pela ampla contribuição dos seus estudos para melhor compreender a problemática em pauta, além de trazer reflexões que nos ajudam a perceber a importância da ampliação do debate acerca da modalidade, dos sujeitos inseridos e dos seus contextos de escolarização, sobretudo neste momento

Educação, Psicologia e Interfaces, Volume 4, Número 3, p. 1-15, Julho/Setembro, 2020.

ISSN: 2594-5343. DOI: 10.37444/issn-2594-5343.v4i3.268 
atual, marcado por retrocessos históricos. Além disso, evidenciam-se as contribuições de Gil (1999) no que se refere a abordagem metodológica do trabalho.

Ao realizar o estudo das obras dos autores supramencionados, foi possível perceber que as distintas faixas etárias que compõem o alunado da EJA carregam particularidades no que diz respeito às características e necessidades, entretanto, Naiff e Naiff (2008, p. 402) ressaltam que muitas vezes a escola se depara com dificuldades na tentativa de entender " [...] as particularidades desse público, no qual os motivos que os levam à evasão, ainda no início da juventude, e as motivações que envolvem sua volta à sala de aula são informações preciosas para quem lida com a questão”. Desse modo, fazse necessário verificar quem são esses sujeitos da EJA e o que buscam na escola, além de questionar sobre a significância da instituição escolar e das experiências vivenciadas nela. De acordo com Dayrell (2001, p.139), nota-se que "Para grande parte dos professores, perguntas como estas não fazem sentido, pois a resposta é óbvia: são alunos”. Na realidade, é possível e necessário a essa categoria observar, por meio das relações que mantém com os jovens e adultos, sua compreensão acerca das atitudes e expectativas demonstradas, de modo que as condições para a realização de diagnósticos dos fatores que interferem de forma positiva ou negativa sobre a evasão e a permanência sejam adquiridas.

Por meio desta pesquisa, busca-se conhecer a trajetória de vida social e escolar dos estudantes da EJA na tentativa de compreender a correlação com o desejo de retornar, permanecer e concluir os estudos na modalidade. E nesse sentido, contribuir para a realização de estudos futuros referentes à temática, bem como fornecer, à comunidade escolar e acadêmica, dados que auxiliem nas reflexões acerca de estratégias contra a dinâmica da evasão.

\section{MATERIAL E MÉTODO}

\subsection{O LÓCUS DA PESQUISA E OS SUJEITOS ENVOLVIDOS}

A pesquisa foi realizada no Colégio Doutor Julival Rebouças, localizado na cidade de Mutuípe, interior da Bahia. Em consonância com os artigos 32 e 37 da Lei de Diretrizes e Bases da Educação Nacional (LDBEN), o colégio-campo de pesquisa contempla os Anos Finais do Ensino Fundamental ( $6^{\circ}$ ao $9^{\circ}$ ano) e os segmentos 1 e 11 da Educação de Jovens e Adultos, sendo o único do município a atender essa modalidade de ensino.

Educação, Psicologia e Interfaces, Volume 4, Número 3, p. 1-15, Julho/Setembro, 2020.

ISSN: 2594-5343. DOI: 10.37444/issn-2594-5343.v4i3.268 
Motivações que influenciam a permanência de jovens e adultos na escola: o que revelam as narrativas dos estudantes do município de Mutuípe?

As narrativas analisadas são provenientes de quatro alunos adultos do segmento $1^{2}$ da modalidade EJA residentes na Zona Rural do município, com idades entre 44 e 56 anos, matriculadas na modalidade há um período igual ou superior a um ano. $\mathrm{O}$ objetivo da delimitação, a partir desse critério, foi compor um grupo que buscasse, mesmo mediante situações desfavoráveis, a continuidade dos estudos, visto que o objeto da pesquisa contempla tal reflexão.

A esses entrevistados foram atribuídos nomes fictícios a fim de manter, por questões éticas, seus verdadeiros nomes preservados. Foram utilizados como critério de escolha os nomes mais populares no país. Nasceram, então, Maria, Ana, João e Antônia. O pronome de tratamento "Dona" e "Seu" foram incorporados aos nomes por assim terem se popularizado.

Dona Maria tem 48 anos de idade, autodeclara-se negra, é lavradora, casada, natural de Mutuípe-Ba, mãe de duas meninas. Reside com seu esposo e uma sobrinha na Zona Urbana do município. Retornou aos estudos no ano de 2017, sendo apoiada pela família. Está cursando o estágio II da modalidade Educação de Jovens e Adultos.

Dona Ana tem 56 anos de idade, autodeclara-se negra, é lavradora, reside na Zona Rural do município com seu esposo e quatro filhos, os quais não apoiaram seu retorno à escola. Está cursando o estágio I da modalidade Educação de Jovens e Adultos.

Seu João tem 47 anos de idade, autodeclara-se negro, exerce a função de lavrador, reside com sua esposa e seus três filhos na Zona Rural do município de Mutuípe-Ba, onde nasceu. Retornou aos estudos no ano de 2018 com apoio de sua família. Está cursando o estágio I da modalidade Educação de Jovens e Adultos.

Dona Antônia tem 44 anos de idade, autodeclara-se branca, está desempregada, reside com seis filhos e esposo no município de origem, Mutuípe-Ba, os quais apoiaram seu retorno aos estudos no ano de 2018. Está cursando o estágio I da modalidade Educação de Jovens e Adultos.

\subsection{CAMINHOS METODOLÓGICOS}

De acordo com Ferreira (1988, p. 472), pesquisar significa "buscar com diligência". Nessa busca por informações, há de se considerar como parte fundamental do processo, a coleta de dados, para tal, fazem-se necessários o cuidado e a presteza.

Educação, Psicologia e Interfaces, Volume 4, Número 3, p. 1-15, Julho/Setembro, 2020.

ISSN: 2594-5343. DOI: 10.37444/issn-2594-5343.v4i3.268 
Assim, insere-se no cotidiano do segmento I da EJA, a fim de verificar os motivos que favorecem a permanência dos adultos $^{3}$ na escola para a continuidade ou conclusão da Educação Básica. Tal inquietação influenciou a busca por experiências na EJA que contribuam para a resposta do problema investigado.

A escolha metodológica utilizada para tal finalidade compreende uma pesquisa exploratória, de natureza qualitativa. E no que tange às técnicas para a coleta e análise de dados, foram aplicadas, respectivamente, observação e entrevista semiestruturada (GIL, 1999; 2008) e análise de conteúdo (BARDIN, 2009).

Portanto, o referido artigo pretende, por meio dos procedimentos supramencionados, aproximar-se da compreensão acerca das razões que mantém os alunos na escola.

\subsection{PROCEDIMENTOS DE RECOLHA E ANÁLISE DOS DADOS}

Para compor a fundamentação teórica, foram consultadas diferentes fontes de cunho científico, consoantes aos objetivos deste estudo: artigos científicos, monografias, dissertações, livros e referências legais. Visando à busca por explicações a respeito do problema, foi realizada a investigação denominada pesquisa de campo (Fonseca, 2002). Assim, para que fosse criada maior familiaridade com o evento pesquisado, a pesquisa exploratória mostrou-se coerente, dada a sua flexibilidade no planejamento e seu objetivo de aproximar o pesquisador dos fatos para a ampliação das interpretações. (GIL, 1999)

Com o propósito de valorizar esse contato, foi adotada a abordagem qualitativa (MINAYO, 2001), delineando a observação e entrevista semiestruturada como principais técnicas para recolha de dados (GIL, 1999; 2008).

De acordo com Gil (1999), a observação representa uma fonte imprescindível para a pesquisa, pois as etapas seguintes são planejadas com base nos resultados obtidos por meio dela. É um dos métodos mais utilizados para inteirar-se de determinados aspectos da realidade, que envolvem as pessoas, as coisas, os fenômenos e os acontecimentos.

Para realizar tal procedimento, a fim de recolher informações sobre os perfis dos alunos que compõem a turma e sobre a rotina e o ambiente nos quais estão inseridos, foi necessário visitar a escola dentro de um período de três semanas, pois, por condições climáticas que dificultavam o deslocamento de áreas rurais, alguns alunos não puderam manter a frequência regular.

Educação, Psicologia e Interfaces, Volume 4, Número 3, p. 1-15, Julho/Setembro, 2020.

ISSN: 2594-5343. DOI: 10.37444/issn-2594-5343.v4i3.268 
Motivações que influenciam a permanência de jovens e adultos na escola: o que revelam as narrativas dos estudantes do município de Mutuípe?

Após a observação das turmas, foi feita uma consulta na lista de matrículas e fichas individuais dos estudantes para verificar quais atendiam aos critérios de escolha estabelecido. Seria necessário ter idade igual ou maior que 44 anos, residir na zona rural e estar matriculado em um período igual ou superior a um ano. A filtragem resultou na classificação de quatro sujeitos empíricos, interlocutores da pesquisa, sendo três mulheres e um homem. Vale ressaltar que, de acordo com informações contidas nos registros, outros alunos poderiam participar da pesquisa, porém, como sinalizado nas listas, muitos haviam evadido ou abandonado a escola antes da conclusão do ano letivo.

A etapa seguinte foi o convite à colaboração com a entrevista. Para isso, julgouse necessário apresentar os objetivos, encaminhamentos e relevância da pesquisa tanto para a formação da autora quanto para a comunidade científica. Como destaca Gil (2008, p. 112), entre as várias técnicas de interrogação,

A entrevista focalizada [...] enfoca um tema bem específico. O entrevistador permite ao entrevistado falar livremente sobre o assunto, mas, quando este se desvia do tema original, esforça-se para a sua retomada. [...] A entrevista focalizada requer grande habilidade do pesquisador, que deve respeitar o foco de interesse temático sem que isso implique conferir-lhe maior estruturação. (GIL, 2008, p. 112)

No processo de recolha de dados, a técnica de entrevista semiestruturada expressa seu caráter flexivo ao permitir que o entrevistado contribua com a investigação de modo mais fluente sem deixar escapar a objetividade.

No que se refere à análise de dados, foi priorizado a Análise de Conteúdo (Bardin, 2009) enquanto método, sistematizando os dados obtidos em categorias de análise, convergindo com os objetivos de estudo.

\section{RESULTADOS E DISCUSSÃO}

Quais as motivações que influenciam a permanência dos estudantes na escola para concluir a Educação Básica? Na tentativa de responder a esta questão, esta seção apresenta os dados revelados no campo empírico e as reflexões à luz das narrativas dos interlocutores.

Educação, Psicologia e Interfaces, Volume 4, Número 3, p. 1-15, Julho/Setembro, 2020.

ISSN: 2594-5343. DOI: 10.37444/issn-2594-5343.v4i3.268 


\subsection{ESTUDANTES DA EJA E AS MOTIVAÇÕES PARA O RETORNO E A PERMANÊNCIA NA ESCOLA: PARA ALÉM DOS DESAFIOS, OS DESEJOS DE NOVAS CONQUISTAS}

Vislumbrar novas possibilidades de inclusão social e ascensão financeira por meio da escolarização é comum para grande parte da população, pois entende-se que a escola representa uma chance para livrar-se de condições sociais e econômicas precárias e desfavoráveis. Se, por um lado, essa perspectiva mobiliza a busca por avanços no processo formativo, por outro, configura uma visão errônea e utópica sobre a educação quando esperam que seus efeitos ponham fim à exclusão e à pobreza. Conforme Almeida (2008, p. 67), há de se considerar que:

Sob esse prisma, a educação é elevada a um nível de endeusamento, como se tudo lhe fosse possível; não se considera seus limites, somente suas possibilidades são evidenciadas. É óbvio que a educação formal é um processo imprescindível para o desenvolvimento material e pessoal de toda e qualquer sociedade. Todavia, existem outras práticas sociais que elevam o ser humano e o faz sujeito que gere uma perspectiva de futuro.

Corroborando a reflexão, Freire (1991) alerta que não se pode acreditar que o fato de saber ler e escrever, por si só, vá contribuir para alterar as condições socioeconômicas como alimentação, moradia, trabalho dentre tantas outras. Tais condições só vão ser de fato alteradas pelas lutas coletivas, pelo enfrentamento, pelas marchas e, sobretudo, por mudanças estruturais da sociedade.

Nessa concepção, os sujeitos não se dão conta de que as pretensões da classe dominante incidem prejudicialmente sobre suas perspectivas, pois os processos escolares são envolvidos por uma esfera de manutenção de privilégios. À vista disto, atribuir unicamente à educação as possibilidades de ascensão pode resultar em desapontamento perante as expectativas fracassadas.

Apesar disso, faz-se importante refletirmos sobre as motivações para o retorno à escola. As narrativas dos sujeitos foram bastante reveladoras ao destacarem os seguintes motivos para a retomada aos estudos, na idade adulta:

Porque eu quero ser professora um dia. Eu sei que pode demorar tempo ainda, mas eu tenho esse desejo dentro de mim, sabe?! Trabalhar na

Educação, Psicologia e Interfaces, Volume 4, Número 3, p. 1-15, Julho/Setembro, 2020.

ISSN: 2594-5343. DOI: 10.37444/issn-2594-5343.v4i3.268 
Motivações que influenciam a permanência de jovens e adultos na escola: o que revelam as narrativas dos estudantes do município de Mutuípe?

roça é difícil. Você se desgasta tanto e nunca melhora de vida. (DONA MARIA, 2018)

Eu quero aprender pra no futuro eu ser alguma coisa. O que eu sempre quis ser, hoje eu não posso mais por causa do atraso nos estudos. Queria ser policial. Meu sonho era esse. Eu acho bonito. (DONA ANA, 2018)

Eu voltei porque eu tenho um desejo tão grande de conseguir ler e entender a Bíblia. Eu vejo todo mundo lendo e eu sem poder, dá uma tristeza. (DONA ANTÔNIA, 2018)

Eu tenho cinco filhos, somente um estuda na roça, mas todos os outros que estudam aqui têm lição pra me dar [praticamente]. Eu pensei assim: eu sendo pai, meus filhos todos quase já concluíram e eu ficar assim? Até o celular, eu não sabia mexer nesses digitais, só nos de tecla mesmo, hoje eu já sei mexer em algumas coisas. (SEU JOÃO, 2018)

As falas de Dona Maria (2018) e Dona Ana (2018) reforçam a concepção de escolarização como o único meio para ascender social e profissionalmente, ou seja, retornar aos estudos significa resgatar a chance de alcançar a profissão desejada e "ser alguém na vida". As reflexões de Arroyo (2000), a seguir, dialogam com as narrativas dos sujeitos e nos convidam a problematizar o processo de escolarização:

Esses vínculos tão caudatários entre escolarização básica e mercado, seletividade, credencialismo, impossibilitaram ao longo deste século a construção de nosso sistema escolar pautado pela concepção de educação básica gestada desde os primórdios da modernidade, na Renascença, consolidada da Ilustração, e até no ideário liberal e, sobretudo, impossibilitavam a incorporação da concepção de educação gestada no pensamento progressista e democrático e nos movimentos e lutas pelos direitos sociais e políticos. (ARROYO, 2000, p. 37)

As discussões de Arroyo (2000) revelam que esse elo criado pela disposição hierárquica das camadas sociais favorece a dinâmica cruel da exclusão, haja a vista que nos últimos tempos a metodologia de seleção e habilitação tem atribuído aos níveis de escolarização a incumbência de classificar ou eliminar candidatos a determinadas vagas de emprego. Nessa lógica, as exigências dos conteúdos programáticos tenderam a aumentar para que os casos de insucesso fossem acentuados. Essa problemática adverte a fragilidade da escola quanto ao objetivo da sua instituição: a priori, dispor dos mesmos privilégios e oportunidades possuídos pela burguesia, favorecendo, assim, as transformações necessárias à sociedade e aos indivíduos para libertarem-se da discriminação causada pela classe dominante.

Educação, Psicologia e Interfaces, Volume 4, Número 3, p. 1-15, Julho/Setembro, 2020.

ISSN: 2594-5343. DOI: 10.37444/issn-2594-5343.v4i3.268 
Dona Antônia (2018) aponta o anseio de ler e entender a Bíblia como justificativa do retorno. Suas falas sinalizam o enorme sentimento de inferioridade, vergonha e descontentamento que o analfabetismo produz, o que acaba favorecendo o surgimento da baixa autoestima. De acordo com Pereira (2004, p. 04), “A autoestima é o fundamento da motivação, pela qual a pessoa se torna produtiva na aprendizagem, no trabalho, nos relacionamentos". Assim, o trabalho com a modalidade da Educação de Jovens e Adultos deve ser motivador e dialogar com os desejos dos estudantes, a fim de significar o processo e promover uma aprendizagem mais produtiva e contextualizada com o contexto e as necessidades do seu público.

Nesta mesma direção, pode ser observada a narrativa do Seu João (2018) que expressa o sentimento de insatisfação pela condição de inferioridade em relação à escolaridade de seus filhos. Foi exatamente isso que o impulsionou a retornar aos estudos na idade adulta. Além disso, reforça que os aprendizados adquiridos na escola também facilitam a utilização de aparelhos tecnológicos.

Para muitos, permanecer na escola representa uma tarefa difícil, entretanto, o desejo de elevar o grau de escolaridade e a expectativa de se beneficiar dos seus efeitos se sobrepõem às dificuldades, isso é explicitado nas falas que justificam a persistência:

Quando o cansaço tá demais eu falto aula, mas não é sempre. Várias vezes eu já pensei em parar de estudar, mas quando eu lembrava de tudo que passei porque não estudei quando tava nova e da minha vontade de ser professora, eu desisto. (DONA MARIA, 2018)

Eu acho tão bonito a pessoa ler e escrever tudo direitinho. Eu tenho vontade de aprender as coisas, a professora vê. O ruim é que tem os problemas de saúde. Eu nem enxergo muito bem, mas tô me esforçando. Eu acho vergonhoso não saber ler. (DONA ANA, 2018)

O que me incentiva a vir pra escola é ouvir as pessoas dizendo que tem uma mulher de 70 anos que estudou até se formar. Com isso a gente vai querendo fazer a mesma coisa pra ver se dá certo. Eu vejo muita gente com idade a mais que eu que consegue concluir. (DONA ANTÔNIA, 2018)

Eu tenho uma vontade de fazer a habilitação porque eu dirijo, sabe? Mas é aquela coisa: a pessoa que é cidadã de bem tem que andar direita. Não adianta eu sair aqui, pegar um carro, o policial vai me olhar, pela minha fisionomia ele vai conhecer que eu sou direito, mas se estiver irregular eu vou passar por errado sem motivo. Aí por isso eu vou em frente! Tirar a carteira e tenho esperança de um dia conseguir um comércio ou que seja uma fazenda. Se eu não tiver um estudo eu não vou conseguir administrar, porque não adianta eu ter 
Motivações que influenciam a permanência de jovens e adultos na escola: o que revelam as narrativas dos estudantes do município de Mutuípe?

uma coisa e não saber administrar, tudo ter que depender dos outros, tudo tem que ser pago. É como dizem: não adianta ter riqueza e não saber o que tem. (SEU JOÃO, 2018)

Apesar de não explicitar outros motivos, além do cansaço, Dona Maria (2018) evidencia que a possibilidade de abandonar os estudos se manifesta com constância, no entanto, reportar aos prejuízos causados pela interrupção da escolarização produz nela os esforços necessários e suficientes para manter a frequência.

Dona Ana (2018) afirmu que a sua permanência está, também, associada à vergonha de não possuir habilidades escolares básicas. Para ela, a leitura e a escrita representarão um escudo contra os constrangimentos sofridos pela condição. Cabe à sociedade compreender que esses estudantes enfrentam tanto no âmbito familiar quanto na vida em comunidade problemas como constrangimento, preconceito, críticas e discriminação.

Dona Antônia (2018) ressalta que o incentivo em permanecer na escola está relacionado ao fato de reconhecer que existem dificuldades maiores que as suas, quando menciona os exemplos de pessoas com idade superior que conseguiram concluir os estudos. Isso afirma a importância de serem divulgados os casos de sucesso, para, conforme destacam Santos, Santos e Ferraz (2014, p. 40), “[...] desconstruir a ideia de que a Educação de Pessoas Jovens e Adultas (EPJA) é o lugar, apenas, dos “fracassados", atendidos por uma proposta desvalorizada".

A intenção de permanecer nos estudos, para Seu João (2018), está relacionada ao desejo de alcançar a autonomia social, além de entender que, para atestar a aptidão para conduzir um veículo automotivo, é necessário ser devidamente instruído pelos saberes escolares e tecnológicos. Outra motivação que o impulsiona é a independência social associada a financeira, já que exprime o desejo de adquirir habilidades que o tornem capaz de administrar o seu próprio negócio no futuro.

Ao serem perguntados se o estudo poderia melhorar sua vida, responderam positivamente:

Claro que pode! Vai melhorar tudo. Só em terminar o ensino médio, conseguir fazer o ENEM, passar, ir pra uma faculdade e terminar tudo, ensinar as crianças, vai ser uma felicidade tão grande depois de quarenta e tantos anos. Já pensou eu ensinando minha neta que vai nascer agora em dezembro? (DONA MARIA, 2018)

Educação, Psicologia e Interfaces, Volume 4, Número 3, p. 1-15, Julho/Setembro, 2020.

ISSN: 2594-5343. DOI: 10.37444/issn-2594-5343.v4i3.268 
Pode melhorar porque o estudo você sai pra algum lugar e não passa dificuldade de saber qual ônibus pegar, de olhar o resultado do exame... (DONA ANA, 2018)

Vai melhorar algumas coisas sim. (DONA ANTÔNIA, 2018)

O estudo pode melhorar minha vida muito mais, em tudo por que se, por exemplo, eu botar um comércio, um mercado hoje eu já tenho como tocar, mas há um ano atrás eu não saberia. (SEU JOÃO, 2018)

Percebe-se que todos esperam melhorias advindas da escolarização, por isso, mantém-se persistentes diante das dificuldades que abarcam o retorno e a permanência. Desta forma, as expectativas depositadas no que o ensino tem a oferecer aos estudantes acentuam a necessidade de atender - com excelência - a essa demanda na Educação de Jovens e Adultos. As apostas dos estudantes perpassam por questões variadas como a carreira acadêmica, a autonomia social e a inserção no mercado de trabalho. Logo, visto que esses estudantes carregam anseios distintos, a escola precisa observar e considerar essa heterogeneidade na sala de aula nas etapas de planejamento, recepção e PPP no sentido de atender a diversidade de faixa etária e sonhos.

\section{CONSIDERAÇÕES FINAIS}

A investigação empírica apontou que as distintas trajetórias escolar e de vida dos estudantes entrevistados constituem um roteiro marcado por injustiças, especialmente social que, na "idade regular", provocou a primeira evasão, denominada também expulsão escolar. O fenômeno decorreu de ações individuais, como desinteresse pelos estudos somado à necessidade de ajudar os pais a prover o sustento da família; e familiares, por parte dos pais que não se preocuparam em garantir o usufruto do direito à educação, mantendo-se omissos à escolarização dos filhos que, buscando a reparação de tal prejuízo, retornaram, já na idade adulta, aos bancos escolares, pois as expectativas em torno das melhorias que a escolarização poderia oferecer impulsionaram os esforços diante das dificuldades de manter a frequência e/ou adquirir aprendizagem.

A partir das narrativas dos estudantes pesquisados, foi possível inferir que o retorno e a permanência ao âmbito escolar visam concluir os estudos para romper com a atual situação econômica e conquistar melhorias trabalhistas, alcançar a satisfação pessoal, atingir um nível suficiente de letramento para seu dia a dia, e vencer o complexo de inferioridade para fortalecer sua autoestima. 
Motivações que influenciam a permanência de jovens e adultos na escola: o que revelam as narrativas dos estudantes do município de Mutuípe?

Concluiu-se que para todos a educação é o fio condutor que os levará à direção correta para superação das condições socioeconômicas em que se encontram. Acreditam que esta é única e suficiente prática social capaz de propiciar resultados satisfatórios. Essa percepção configura uma utopia, visto que, apesar de os objetivos e características da EJA serem amparados legalmente pela LDB (9.394/96), é sabido que essa modalidade de ensino ainda não assegura a qualidade da educação condizente às expectativas desses sujeitos.

Diante do exposto, este estudo evidenciou que a permanência na escola está correlacionada a aspiração de um futuro melhor em que as disparidades sociais e econômicas não atravessem suas vivências.

Às instituições escolares, cabe a responsabilidade de construir um trabalho de qualidade. Apesar de não ser uma tarefa fácil, merece cuidado e atenção por parte da gestão escolar, visto que o público atendido pela modalidade é composto por pessoas que não tiveram acesso à educação dita regular. Assim, faz-se necessário atentar aos métodos que definem a qualidade dos serviços públicos educacionais prestados a esses sujeitos de modo que a certificação tão almejada possibilite, além da ascensão e autonomia vislumbradas, a formação de cidadãos dotados de reflexão e criticidade com disposição e capacidade para interagir de forma participativa nos espaços sociais como acertadamente sugerem as concepções freireanas.

\section{Notas de rodapé}

${ }^{1}$ A integração do termo se deu pelo reconhecimento da "existência" de idosos na modalidade, entretanto, cabe ressaltar a ausência no corpus da pesquisa.

${ }^{2} \mathrm{O}$ segmento I da Educação de Jovens e Adultos corresponde aos anos iniciais do Ensino Fundamental. É Composto por dois estágios: I correspondente aos $2^{\circ}$ e $3^{\circ}$ anos e II aos $4^{\circ}$ e $5^{\circ}$ anos.

${ }^{3} \mathrm{O}$ realce do termo adulto se deu em razão da idade dos sujeitos da pesquisa.

\section{REFERÊNCIAS BIBLIOGRÁFICAS}

ALMEIDA, Miguel Rodrigues. Educação de Jovens e Adultos no município de Senhor do Bonfim-BA: relação entre a prática docente e a evasão escolar. 2008. 99f. Dissertação (Mestrado em Educação) - Instituto de Agronomia, Universidade Federal Rural do Rio de Janeiro, Seropédica, 2008.

ARROYO, Miguel. Fracasso/Sucesso: um pesadelo que perturba nossos sonhos. In: Em aberto, Brasília, v. 17, nº.71, p. 33 - 40, janeiro 2000.

BARDIN, L. Análise de Conteúdo. Lisboa, Portugal; Edições 70, LDA, 2009.

Educação, Psicologia e Interfaces, Volume 4, Número 3, p. 1-15, Julho/Setembro, 2020.

ISSN: 2594-5343. DOI: 10.37444/issn-2594-5343.v4i3.268 
BRASIL. Ministério da Educação. Parecer CNE/CEB nº 15/1988.

Programa Nacional de Integração da Educação Profissional com a Educação Básica na Modalidade de Educação de Jovens e Adultos (Proeja). Brasilia: SETEC/MEC, 2007. Disponível em: http:/portal.mec.gov.br/proeja. Acesso em: 22 de fevereiro de 2018

DAYRELL, Juarez. Múltiplos olhares sobre a educação. Editora UFMG. Belo Horizonte. 2001.

FERREIRA, Aurélio Buarque de Holanda. Dicionário Aurélio Básico da Língua Portuguesa. Rio de Janeiro: Nova Fronteira, 1988, p. 472

FONSECA, J. J. S. Metodologia da pesquisa científica. Fortaleza: UEC, 2002. Apostila.

FREIRE, Paulo. Pedagogia da autonomia: saberes necessários à prática educativa. São Paulo, SP: Paz e Terra, 1996.

A Educação na Cidade. São Paulo: Cortez; 1991

GHIRALDELLI JUNIOR, Paulo. "Entrevista: O Plano do heroísmo". In. Revista Educação nº. 129, Janeiro 2008. São Paulo: Editora Segmento, p. 4 a 6, 40 a 45.

GIL, Antonio Carlos. Métodos e técnicas de pesquisa social. 5.ed. São Paulo: Atlas, 1999.

MINAYO, Maria Cecília de Souza (org.). Pesquisa Social. Teoria, método e criatividade. 18 ed. Petrópolis: Vozes, 2001.

NAIFF, Denis Giovani Monteiro; NAIFF, Luciene Alvez Miguez. Educação de Jovens e Adultos em uma análise psicossocial: representações e práticas sociais. Psicologia \& Sociedade, v. 20, n. 3. Rio de Janeiro. 2008.

PEREIRA, Ayle Azeredo Gonçalves. O que está dentro é o que define o preço: ajudando alunos com problemas de auto-estima por razões físicas. 2004. Monografia (Pós-Graduação Lato Sensu) - Faculdade de Educação, Universidade do Estado do Rio de Janeiro, Rio de Janeiro, 2004.

SANTOS, Gabriela da Silva dos; SANTOS, José Jackson Reis dos; FERRAZ, Cristiano Lima. Razões de permanência na educação de pessoas jovens e adultas: reflexões sobre a infância, trabalho e escolarização. In: SANTOS, José Jackson Reis dos; PEREIRA, Sandra Márcia Campos; ARAGÃO, José Wellington Marinho de; (Orgs.). Alfabetizar crianças e pessoas jovens, adultas e idosas: reflexões e análise de propostas. Salvador: EDUNEB, 2014.

\section{Credenciais da/os autora/es}

SANTOS, Marilene Souza dos. Graduada em Pedagogia em Universidade Federal do Recôncavo da Bahia (UFRB). E-mail: day_cj@hotmail.com

ANDRADE, Maria Eurácia Barreto de. Professora na Universidade Federal do Recôncavo da Bahia (UFRB), com atuação no Centro de Formação de Professores (CFP). Doutora em Educação (UA). E-mail: mariaeuracia@ufrb.edu.br

Educação, Psicologia e Interfaces, Volume 4, Número 3, p. 1-15, Julho/Setembro, 2020. ISSN: 2594-5343. DOI: 10.37444/issn-2594-5343.v4i3.268 
Motivações que influenciam a permanência de jovens e adultos na escola: o que revelam as narrativas dos estudantes do município de Mutuípe?

Endereço para correspondência: Marilene Souza dos Santos. Rua: Conceição de Almeida, $n^{\circ}$ 05, Cajazeiras, CEP: 45480-000, Mutuípe/Bahia. E-mail: day_cj@hotmail.com

Como citar este artigo (Formato ABNT): SANTOS, Marilene Souza dos. Motivações que influenciam a permanência de jovens e adultos na escola: o que revelam as narrativas dos estudantes do município de Mutuípe? Educação, Psicologia e Interfaces, v. 4, n.2, p. $1-15,2020$.

Recebido: 07/04/2020.

Aceito: 20/05/2020. 